\title{
\#USES
}

science for a changing world

Prepared in cooperation with the Bureau of Land Management

\section{Injection-Site Reactions in Wild Horses (Equus caballus) Receiving an Immunocontraceptive Vaccine}

Scientific Investigations Report 2009-5038

U.S. Department of the Interior U.S. Geological Survey 
Cover photograph. Jason I. Ransom, U.S. Geological Survey. 


\title{
Injection-Site Reactions in Wild Horses (Equus caballus) Receiving an Immunocontraceptive Vaccine
}

\author{
By James E. Roelle and Jason I. Ransom
}

Prepared in cooperation with the Bureau of Land Management

Scientific Investigations Report 2009-5038 


\title{
U.S. Department of the Interior \\ KEN SALAZAR, Secretary
}

\author{
U.S. Geological Survey \\ Suzette M. Kimball, Acting Director
}

U.S. Geological Survey, Reston, Virginia: 2009

For product and ordering information:

World Wide Web: http://www.usgs.gov/pubprod

Telephone: 1-888-ASK-USGS

For more information on the USGS — the Federal source for science about the Earth,

its natural and living resources, natural hazards, and the environment:

World Wide Web: http://www.usgs.gov

Telephone: 1-888-ASK-USGS

\footnotetext{
Any use of trade, product, or firm names is for descriptive purposes only and does not imply endorsement by the U.S. Government.

Although this report is in the public domain, permission must be secured from the individual copyright owners to reproduce any copyrighted material contained within this report.
}

Suggested citation:

Roelle, J.E., and Ransom, J.I., 2009, Injection-site reactions in wild horses (Equus caballus) receiving an immunocontraceptive vaccine: U.S. Geological Survey Scientific Investigations Report 2009-5038, 15 p. 


\section{Contents}

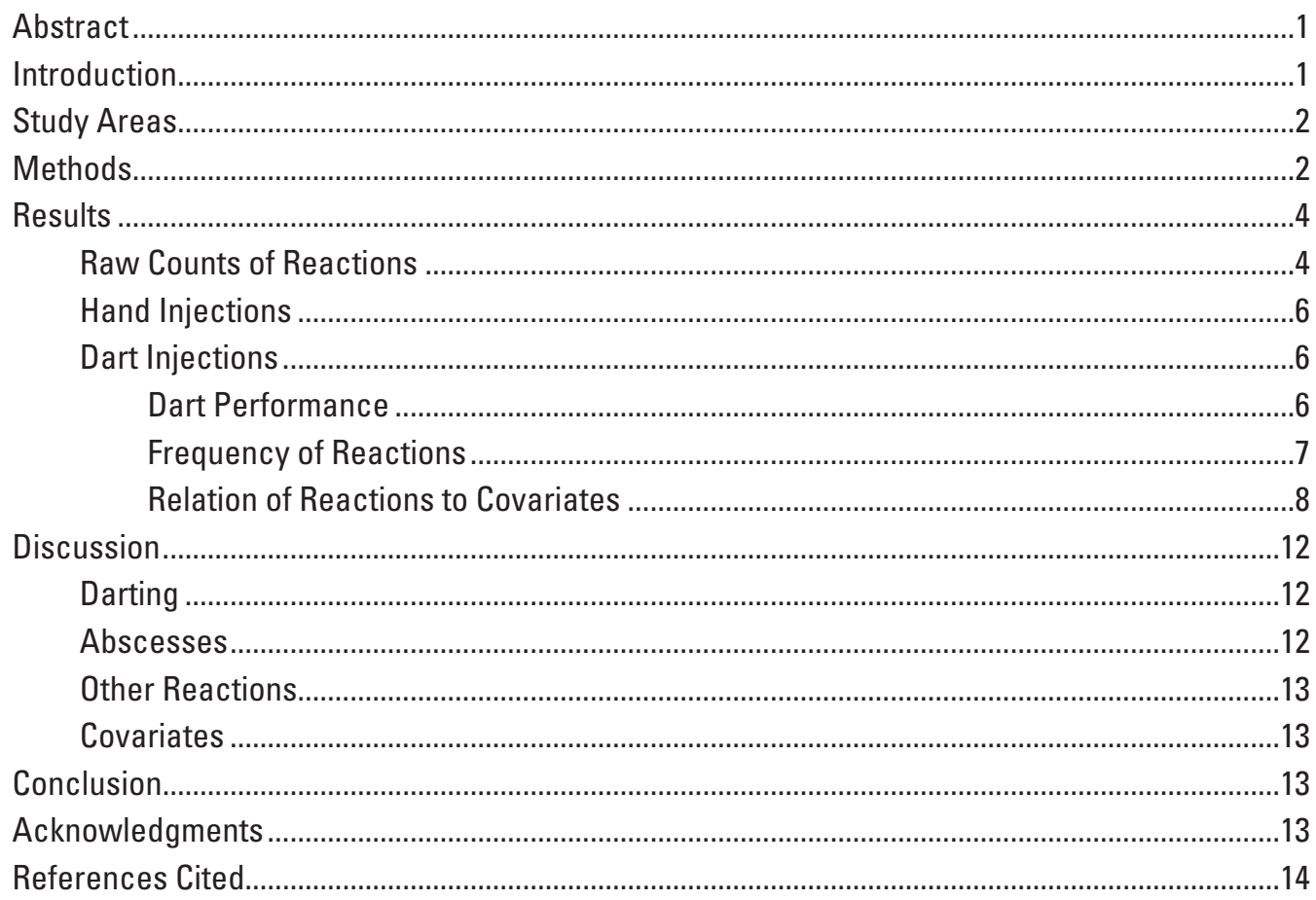

\section{Figures}

1. Abscess observed on Pryor Mountain horse \#8901, 32 days after a booster injection delivered by $\mathrm{CO}_{2}$ blowgun............................................................................

2. Two nodules observed on Pryor Mountain horse \#9105, 2 years $(A)$ and 56 days $(B)$ after booster injections delivered by $\mathrm{CO}_{2}$ blowgun ..................................................

3. Example of a dart used for all injections.........................................................................

\section{Tables}

1. Raw counts of injection-site reactions observed. Includes reactions from

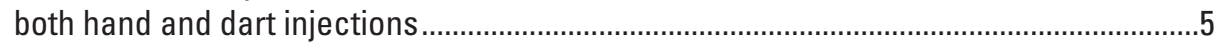

2. Performance of darts used in delivering the immunocontraceptive vaccine...................7

3. Percentage of injection sites exhibiting abscesses, nodules, swelling, or stiffness as a function of time after injection................................................................

4. Relation between occurrence of nodules and the covariates dart trauma, adjuvant, delivery method, and age of mare ....................................................................

5. Relation between occurrence of swelling and the covariates dart trauma,

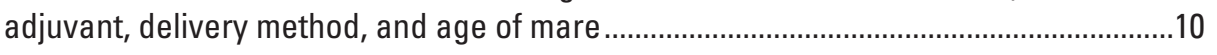

6. Relation between occurrence of stiffness and the covariates dart trauma, adjuvant, delivery method, and age of mare. 


\title{
Injection-Site Reactions in Wild Horses (Equus caballus) Receiving an Immunocontraceptive Vaccine
}

\author{
By James E. Roelle ${ }^{1}$ and Jason I. Ransom ${ }^{1}$
}

\section{Abstract}

The U.S. Geological Survey and the Bureau of Land Management are conducting research on the efficacy of the immunocontraceptive agent porcine zona pellucida (PZP) in reducing fertility of wild horses (Equus caballus). As an antigen, PZP stimulates antibody production when injected into many mammalian species. These antibodies bind to the external surface of the ovum, preventing fertilization. By itself, PZP is only weakly immunogenic and is therefore delivered with an adjuvant, most commonly one of the Freund adjuvants, designed to further stimulate antibody production. Freund's complete adjuvant (FCA) in particular is known to be very effective, but may also be associated with undesirable side effects such as formation of abscesses at injection sites. Such reactions may be exacerbated when accompanied by the additional trauma of a remotely delivered dart. Because horses in our three study herds were individually identifiable by color markings and harem association, we were able to monitor mares for injection-site reactions (abscesses, nodules, swelling, and stiffness) following inoculation with PZP.

In 100 injections delivered by hand we observed a single nodule, two instances of swelling, and no other reactions. In two herds that received remotely delivered (dart) injections, the frequency of reactions was about 1 and 6 percent for abscesses, 25 percent for nodules (both herds), 11 and 33 percent for swelling, and 1 and 12 percent for stiffness. Abscesses were too infrequent to allow meaningful analysis of the relation to covariates, but for the other types of reactions we used logistic regression to examine the relation of occurrence to the delivery method (rifle or $\mathrm{CO}_{2}$-powered blowgun), adjuvant (FCA, Freund's modified adjuvant, and Freund's incomplete adjuvant), dart trauma (normal or abnormal), and age of mare. Abnormal dart trauma included cases where the dart hit bone or the needle broke off. We found strong evidence (odds ratio $=5.023, P=0.001$ ) for a higher probability of occurrence of swelling when darts were delivered by blowgun. We found some evidence (odds ratio $=8.729, P=0.07$ ) that abnormal dart trauma led to a higher frequency of nodule formation. Nodules were the most common reactions observed and often persisted for a year or

${ }^{1}$ U.S. Geological Survey, Fort Collins, Colorado. more, but in our observations they did not appear to change any animal's range of movement or locomotor patterns and in most cases did not appear to differ in magnitude from naturally occurring injuries or scars. We were unable to perform histological examinations of these nodules, but they may be similar to granulomas reported by other investigators following administration of Freund's adjuvant.

\section{Introduction}

The Wild Free-Roaming Horses and Burros Act of 1971 (P.L. 92-195, as amended) declared that "wild free-roaming horses and burros are living symbols of the historic and pioneer spirit of the West" and that these animals "shall be protected from capture, branding, harassment, or death." Responsibility for management of wild horses (Equus caballus) and burros (Equus asinus) on western lands was vested in the Bureau of Land Management (BLM) and the U.S. Department of Agriculture Forest Service (FS). BLM, our partner in the research described here, currently manages wild horses and burros on 199 Herd Management Areas (HMAs) encompassing over 13.9 million hectares. Given the protection afforded by the Act and largely unchecked by natural predators, wild horse populations can increase rapidly, often 15-25 percent per year (Eberhardt and others, 1982; Garrott and Taylor, 1990; Garrott and others, 1991) and can quickly exceed the capacity of the range to support them. Historically, BLM has managed excess animals by gathering them (every 3-5 years on most HMAs) and offering them for adoption or sale to good homes. More recently, BLM has sought to diversify its management program through the use of contraception to slow population growth.

In 2001, BLM and the U.S. Geological Survey (USGS), Fort Collins Science Center, initiated research to study the efficacy of the immunocontraceptive agent porcine zona pellucida (PZP) in limiting the fertility of mares in three horse herds in the Western United States: Little Book Cliffs Wild Horse Range (LBC) in Colorado, McCullough Peaks Herd Management Area (MCP) in Wyoming, and Pryor Mountain Wild Horse Range (PRY) in Montana and Wyoming. (See Kirkpatrick and Frank [2005] for a recent review of contraception in equids and other free-ranging animals.) PZP is produced from 
pig ovaries and acts as an antigen when injected into other species. PZP stimulates production of antibodies that bind to the zona pellucida, or external surface of the ovum, of the host species and interfere with fertilization (Asa, 2005). PZP by itself is only weakly antigenic and is usually delivered with an adjuvant to further stimulate the host immune system to produce antibodies. The adjuvant of choice for PZP applications in equids, at least for the first inoculation, has most often been Freund's complete adjuvant (FCA) (see, for example, Kirkpatrick and others, 1990; Turner and others, 1996, 1997, 2001). While very effective, FCA can have undesirable side effects, including the formation of abscesses and granulomas at the injection site, which appear to depend on the species, delivery method (hand injection or dart), injection location, and injection route (for example, intramuscular, subcutaneous) (Mahi-Brown and others, 1985; Broderson, 1989; Claassen and others, 1992; Leenaars and others, 1994, 1998; Lyda and others, 2005). In addition, accidental exposure to FCA can be hazardous to those administering the injections (Chapel and August, 1976).

In view of the potential for such adverse reactions, quantification of their occurrence is desirable. However, followup observations of injection sites is not often possible with free-ranging animals because individual animals are not easily identified unless they are marked (for example, with brands or ear tags) when treated (but see Naugle and others [2002] for an example involving individually recognizable white-tailed deer [Odocoileus virginianus]). In our three study herds, however, horses were individually recognizable through color markings and band (harem) associations, thus offering an opportunity to observe reactions at contraceptive injection sites. Here, we report the results of those observations; information on contraceptive efficacy will be presented elsewhere.

\section{Study Areas}

The Little Book Cliffs Wild Horse Range is located in Mesa County, Colorado, about $13 \mathrm{~km}$ northeast of Grand Junction and consists of 14,614 ha of sloping plateaus, sagebrush parks, steep-walled shale and sandstone cliffs, and four major canyon systems. A Wilderness Study Area (WSA) comprises 10,734 ha of the range and limits access by motorized vehicle. During our study, the herd was distributed across the entire range. Some horses traveled seasonally between the lower canyons and the higher elevations, and others did not move seasonally. Locating individual horses was often complicated by the predominance of Colorado piñon (Pinus edulis) and Utah juniper (Juniperus osteosperma) in association with the rough terrain. Once located, horses were generally approachable to within adequate observation distance using binoculars or spotting scopes; however, certain horses exhibited restless behavior when observers were present in wooded areas and would flee before detailed observation data could be collected.

The McCullough Peaks Herd Management Area is located in Park County, Wyoming, $32 \mathrm{~km}$ east of the town of Cody. It consists of 44,440 ha of predominantly flat, open sagebrush steppe, with rugged badlands along the western edge. A WSA occupies 9,943 ha of the range. There was no single seasonal congregation area for horses, though the majority of the population resided in the southern half of the range during our study. Horses on this portion of the range were generally quite visible due to the nature of the terrain and vegetation, but they were not approachable. Observation of injection sites was thus difficult, even with the aid of a spotting scope.

The Pryor Mountain Wild Horse Range is located $21 \mathrm{~km}$ north of Lovell, Wyoming, and lies within northern Bighorn County, Wyoming, and southeastern Carbon County, Montana. The range includes BLM land, portions of Custer National Forest and Bighorn Canyon National Recreation Area, and private lands, and consists of 16,046 ha of lowland desert, foothill slopes, forested montane slopes, steep canyons, and grassy plateaus. Three WSAs occupy the majority of PRY, limiting motorized access to the sparse road system. Vegetation types vary greatly from lower to higher elevations of the range, with lower elevations dominated by big sagebrush (Artemisia tridentata), mid-elevations dominated by curl-leaf mountain mahogany (Cercocarpus ledifolius), Utah juniper, and various grasses, and high elevations dominated by limber pine (Pinus flexilis), subalpine fir (Abies lasiocarpa), and alpine bluegrass (Poa alpina). Most horses moved from lower and mid-elevations in winter to high elevations in summer. Thus, horses were usually easy to observe in summer when they were in open subalpine and alpine meadows, but difficult to observe in spring and fall on forested montane slopes. Horses at PRY did not generally react to humans and, once located, could be closely approached for detailed observation.

\section{Methods}

We initiated treatments at each of the three study areas in concert with gathers scheduled by BLM (PRY in 2001, LBC in 2002, MCP in 2004). Ages and numbers of horses treated were in accordance with local plans developed by BLM (U.S. Department of the Interior, Bureau of Land Management, 2001, 2002, 2004). At LBC and MCP, mares of all ages $\geq 1$ year were included. At PRY, however, we treated only mares 1-2 years old or $>15$ years old. At LBC and PRY, mares that were gathered received an initial inoculation (primer) by handheld syringe or jabstick while restrained in a squeeze-chute, ungathered mares (sufficient to make up the total number of desired treatments) received the primer injection by remotely delivered dart, and all mares received a second inoculation (booster) by dart. At MCP, all inoculations were given in a squeeze-chute by hand-held syringe, jabstick, or hand-held trocar. All inoculations, regardless of delivery method, were given in the hip.

At LBC and PRY, primer injections consisted of $0.5 \mathrm{~mL}$ $(100 \mu \mathrm{g})$ PZP and $0.5 \mathrm{~mL}(100 \mu \mathrm{g})$ FCA or Freund's modified adjuvant (FMA), and boosters consisted of $0.5 \mathrm{~mL}(100 \mu \mathrm{g})$ 
PZP and $0.5 \mathrm{~mL}(100 \mu \mathrm{g})$ Freund's incomplete adjuvant (FIA). Adjuvants and PZP were provided by the Science and Conservation Center at ZooMontana in Billings. Darts were propelled from a Dan-Inject ${ }^{\circledR}$ (Dan-Inject of North America, Knoxville, Tenn.) $\mathrm{CO}_{2}$-powered blowgun, a Dan-Inject ${ }^{\circledR} \mathrm{CO}_{2}$ rifle, or a Pneu-dart ${ }^{\circledR}$ (Pneu-Dart, Williamsport, Pa.) 193 rifle. The $\mathrm{CO}_{2}$ delivery systems allowed user-defined power in pounds of pressure per square inch. The Pneu-dart rifle used .22 caliber $\mathrm{CCI}^{\circledR}$ (CCI, Lewiston, Idaho) green power-level charges that were individually weighed to ensure consistent delivery force. Abnormally light and abnormally heavy charges were discarded. Darts used in all delivery systems were 1-cc Pneudart darts with 3.8-cm barbless needles. These injections of liquid PZP at LBC and PRY were designed to provide 1 year of infertility, with annual boosters extending the period of contraception.

Treatment at MCP consisted of a primer injection (same composition as for the other two herds with FCA as the adjuvant) delivered by either hand-held syringe or jabstick and a second (but simultaneous) injection delivered by trocar and consisting of three pellets designed to release PZP in bolus fashion at 1, 3, and 12 months postinjection and provide 2 years of infertility. Pellets were developed at the Medical College of Ohio (now the College of Medicine, University of Toledo) and were formed using an organic solvent to mix polymer with PZP and the saponin adjuvant QA-21. The polymer was a mixture of polylactic acid and glycolic acid (both approved for use in humans by the Food and Drug Administration), with the ratio of the two components dependent on the desired release time. Subsequent evaporation of the solvent resulted in a polymer/PZP/adjuvant mixture viscous enough to be formed into pellets that were cut to the desired mass and loaded into a trocar for delivery (J. Turner, Jr., University of Toledo College of Medicine, written commun., 2005).

Liquid vaccine was provided as sterile components (PZP and adjuvant) that were emulsified in alcohol-sterilized syringes prior to application. For hand injections, the emulsion was loaded into alcohol-sterilized syringes fitted with singleuse sterile needles. For remote delivery, the emulsion was loaded into darts as they were removed from the manufacturer's packaging, and a small dab of petroleum jelly was placed on the dart tip to prevent leakage of the vaccine. Pellets were dipped in alcohol, coated with a thin film of petroleum jelly, and loaded into sterile needles at the place of manufacture. Each needle tip was also closed with a small dab of petroleum jelly to prevent the pellets from slipping out of the needle during handling. For all hand injections, hip hair was shaved and the area washed with alcohol prior to immunization (J. Turner, Jr., written commun., 2008).

Mares treated at gathers were held in corrals for 28-48 hours and observed for any reactions to injections, then released back to the range. Following remotely delivered treatments, we immediately recovered the dart (if possible) and recorded information on its condition and performance. We then attempted to observe the animal for 30 minutes, which was sometimes not possible for those that fled. We also attempted, with varying degrees of success, to observe each injection site once per week for the first 3-4 weeks or until any reaction disappeared. Additional observations were recorded opportunistically for up to 6 years. Observation distances ranged from $1 \mathrm{~m}$ to $500 \mathrm{~m}$, with various optical devices (binoculars, spotting scopes) employed at longer distances. We tracked multiple injections to the same individual by carefully noting the location of each injection on the mare and specifically referencing each new injection site to any observed reactions from previous injections. We also took photographs of reactions opportunistically to aid in referencing specific injection locations.

We coded injection-site reactions in four categories: abscess (an open sore, usually with drainage), nodule (a well-defined circular lump of unknown histology), swelling (a raised area of tissue, but not sufficiently well defined to be considered a nodule), or stiffness (any abnormal range of movement in the limb where the injection was delivered). These categories were not mutually exclusive with respect to either a single observation or a single injection. Swelling and stiffness, for example, were sometimes recorded for the same observation, and multiple reactions were sometimes recorded for a single injection site (for example, swelling might develop into a nodule). We also looked for muscle tremors, behavioral depression, or other systemic reactions, none of which was ever observed.

Because of the opportunistic nature of many of our observations, we could not calculate frequency of occurrence of injection-site reactions directly from the raw data. For example, if an injection site was observed on days 0 and 180 , and no reaction was seen, it would be inappropriate to conclude that no reaction occurred because a reaction could have developed and disappeared in the time between the two observations. As an alternative, we divided all of our observations into a series of intervals representing elapsed time after the injection and calculated the frequencies with which the four types of reactions were observed in each interval. Multiple observations of an injection site in a given mare in a period were counted as a single observation in determining sample size, and the reaction was coded as present if it was recorded for any observation during the period. For this analysis, as well as the analysis of covariates (see below), we excluded all injections that were given by hand because much of the concern about possible injection-site reactions in horses is related to darting.

The fact that abscesses occurred infrequently, coupled with the fact that four of the eight observed abscesses occurred in a single horse, precluded meaningful analysis of the relation of abscess occurrence to covariates. For the remaining types of reactions (nodules, swelling, and stiffness), we used logistic regression (PROC LOGISTIC in SAS/STAT ${ }^{\circledR}$; SAS Institute, Cary, N.C.) to examine the relation between occurrence and four covariates: adjuvant (FCA, FMA, or FIA), delivery method, dart trauma, and age of the mare. For delivery method, we used two classes: rifle or blowgun. We pooled deliveries from the Dan-Inject ${ }^{\circledR} \mathrm{CO}_{2}$ rifle with those from the Pneu-Dart ${ }^{\circledR}$ 
193 rifle because both were scoped delivery guns with longer range, even though the $\mathrm{CO}_{2}$ rifle allowed user-defined power. In addition, the sample size for treatments delivered with the $\mathrm{CO}_{2}$ rifle was small $(n=8)$. For dart trauma, we divided the injections into two broad classes: those where the result may have caused additional trauma at the injection site (bone plug or needle broke off, which we labeled as abnormal) and all others (normal). We did not include the distance from which the dart was fired in this analysis because (1) there were some cases in which distance was not recorded (which would reduce our sample size) and (2) distance tended to be highly correlated with method. Probabilities reported from these regressions are based on the Wald chi-square test statistic.

As noted above, there were many injection sites that were not observed early enough or often enough to be certain whether the various reactions occurred. Therefore, we had to establish criteria for including an injection in the analysis of possible covariates, and those criteria differed by reaction type. Swelling and stiffness, for example, tended to appear earlier and disappear more quickly than nodules. After careful examination of the data, we arrived at the following criteria: for nodules, at least one observation between days 7 and 90 postinjection, inclusive; and for swelling and stiffness, at least one observation between days 0 and 7 postinjection, inclusive. Note that, for these analyses, we are concerned only with whether or not a reaction occurred, not with how long it persisted. In all of these analyses, we pooled data from LBC and PRY in order to maximize sample size.

\section{Results}

Thirty-six mares treated at MCP received 72 injections by hand-held syringe, jabstick, or trocar. Because reactions from these hand injections were very rare (see section on Hand Injections, below), and because of the difficulty of observing injection sites at the distances involved, we made only limited followup observations at MCP after the horses were released back to the range. For LBC and PRY combined, 90 mares received a total of 314 injections in 2001-2007. Five mares representing eight injections were not observed postimmunization, leaving us with 714 individual observations of 133 injection sites on 29 mares at LBC and 726 observations of 173 injection sites on 56 mares at PRY (85 total mares, 306 total injections, 1,440 total observations). The majority of injections at LBC and PRY were remotely delivered by dart; 28 were delivered by hand.

\section{Raw Counts of Reactions}

For the three areas combined, eight injections resulted in abscesses (table 1). Four of the five abscesses at LBC occurred on a single mare. Six of the eight abscesses were first observed within 39 days of the injection, but we cannot be more definitive about when they formed. One abscess appeared at least 24 days after the injection. Six of the eight abscesses were resolved by the time our formal observations ended in the fall of 2007. One of the two unresolved abscesses at PRY was from a recent injection (July 7, 2007). This abscess had resolved by the time she was first observed in 2008. The other was an abscess that was first observed on day 329 postinjection (we do not know when it formed). The mare subsequently developed a large wound in the same location, which prevented further observation of the injection site. A veterinary examination in September 2007 concluded that the muscle tissue was not infected but was inconclusive in determining whether the wound resulted from the PZP injection, dart penetration, or some natural cause. When observed in April 2008, the large wound had resolved with scar tissue evident, but no further external sign of the abscess was present. The mean diameter for all abscesses $( \pm$ SE) was $3.3 \pm$ $0.37 \mathrm{~cm}(n=9$ observations of 8 abscesses, range $=1-5 \mathrm{~cm})$. Figure 1 illustrates a typical abscess.

Nodules were observed more often than abscesses and more often remained unresolved at the end of our observations (table 1). Nodules formed as early as the day of the injection, and 51 were first observed within 90 days postinjection; the remaining 11 may have appeared in this period also, but we cannot confirm this from our observations. Seventeen nodules appeared at least 8 days postinjection, and one nodule appeared at least 48 days postinjection. While nodules often persisted for long periods ( 26 were observed at least 1 year postinjection), persistence did not preclude eventual disappearance (for example, one disappeared after at least 1,337 days and another after at least 1,114 days). Mean nodule size was $2.8 \pm 0.10 \mathrm{~cm}$ ( $n=194$ observations of 62 nodules, range $=1-12 \mathrm{~cm})$. Figure 2 illustrates two typical nodules.

Swelling was the second most common reaction (after nodules; table 1) and usually appeared soon after the injection; 28 of the instances that we observed were recorded on the day of the injection or the following day. At least 26 of the instances of swelling disappeared within 30 days postinjection, although one was still present at 62 days. The two instances of unresolved swelling represent sites that were last observed (in 2007) 28 and 33 days postinjection. Mean swelling diameter at LBC and PRY was $4.6 \pm 0.35 \mathrm{~cm}(n=64$ observations of 49 cases of swelling, range $=1-12 \mathrm{~cm}$ ). The two instances of swelling at MCP (from hand injections) were both $2 \mathrm{~cm}$ in diameter.

Stiffness resulted from 1 injection at LBC and 14 at PRY. Stiffness usually developed shortly after the injection; in 11 of the 15 cases it was observed in the first 3 days postinjection. In most cases, stiffness lasted a relatively short time; in 11 of 15 cases it disappeared within 24 days postinjection. This may also be the case for the remaining four injections, but our observations were not sufficiently frequent to narrow the time of disappearance.

Multiple reactions were recorded for only 10 of 1,440 (0.7 percent) individual observations. A combination of swelling and stiffness accounted for eight of these observations, with the other two involving stiffness and a nodule, 
Table 1. Raw counts of injection-site reactions observed. Includes reactions from both hand and dart injections.

[- = not applicable $]$

\begin{tabular}{lccccc}
\hline & \multicolumn{2}{c}{ LBC } & & MCP & PRY \\
\cline { 2 - 6 } & Hand injection & Dart injection & Hand injection & Hand injection & Dart injection \\
\hline Abscesses observed $^{1}$ & 0 & 5 & 0 & 0 & 3 \\
Abscesses resolved $^{1}$ & - & 5 & - & - & 1 \\
Nodules observed $^{1}$ & 1 & 17 & 0 & - & 44 \\
Nodules resolved $^{1}$ & 1 & 12 & - & 0 & 24 \\
Swelling observed & 0 & 8 & 2 & - & 41 \\
Swelling resolved $^{1}$ & - & 1 & 0 & - & 39 \\
Stiffness observed & 0 & 1 & - & - & 14 \\
Stiffness resolved $^{1}$ & - & 8 & & & 14 \\
\hline
\end{tabular}

${ }^{1}$ Resolved indicates that the reaction had disappeared by the end of our observations in fall 2007.

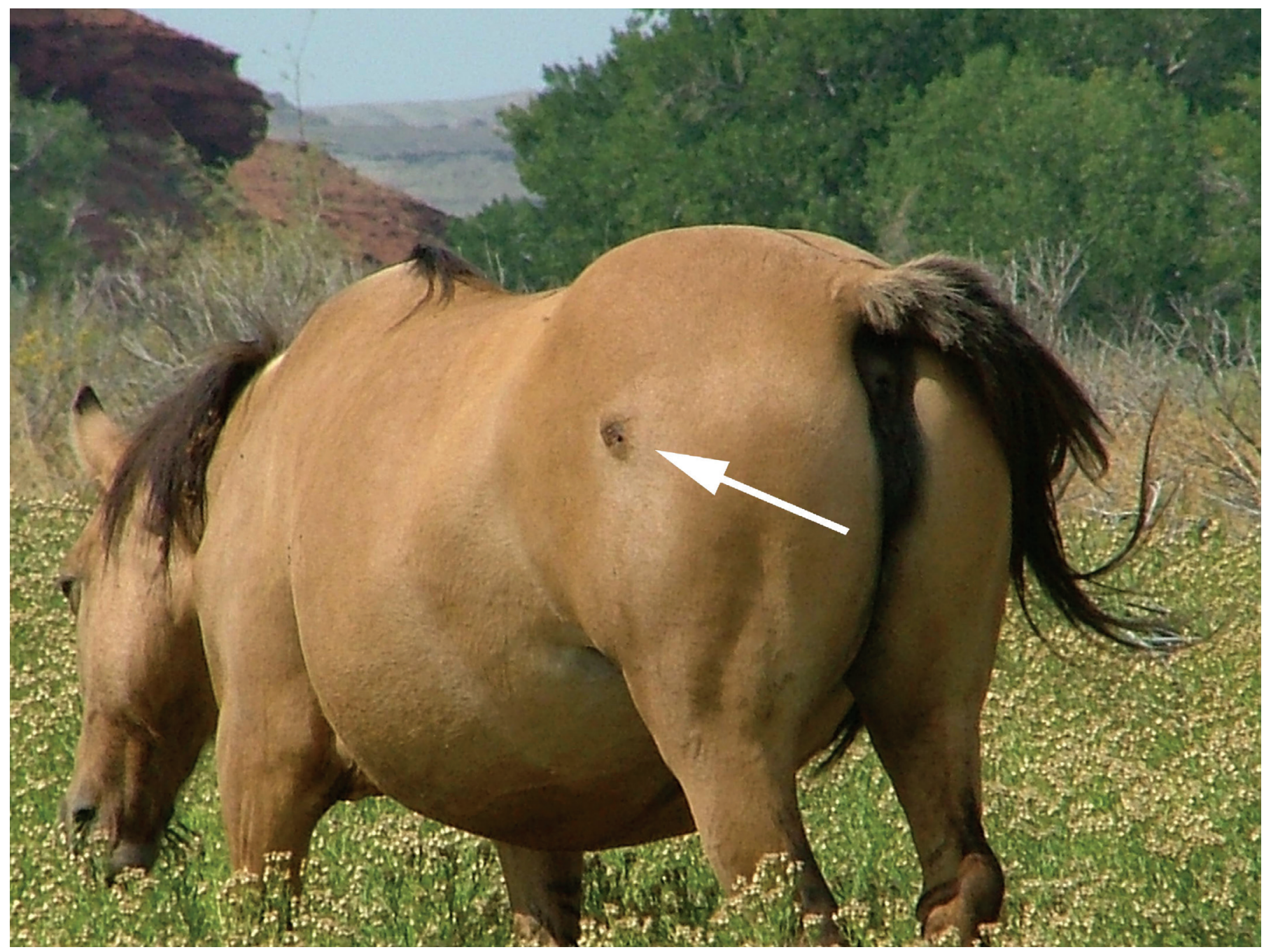

Figure 1. Abscess observed on Pryor Mountain horse $\# 8901,32$ days after a booster injection delivered by $\mathrm{CO}_{2}$ blowgun. 


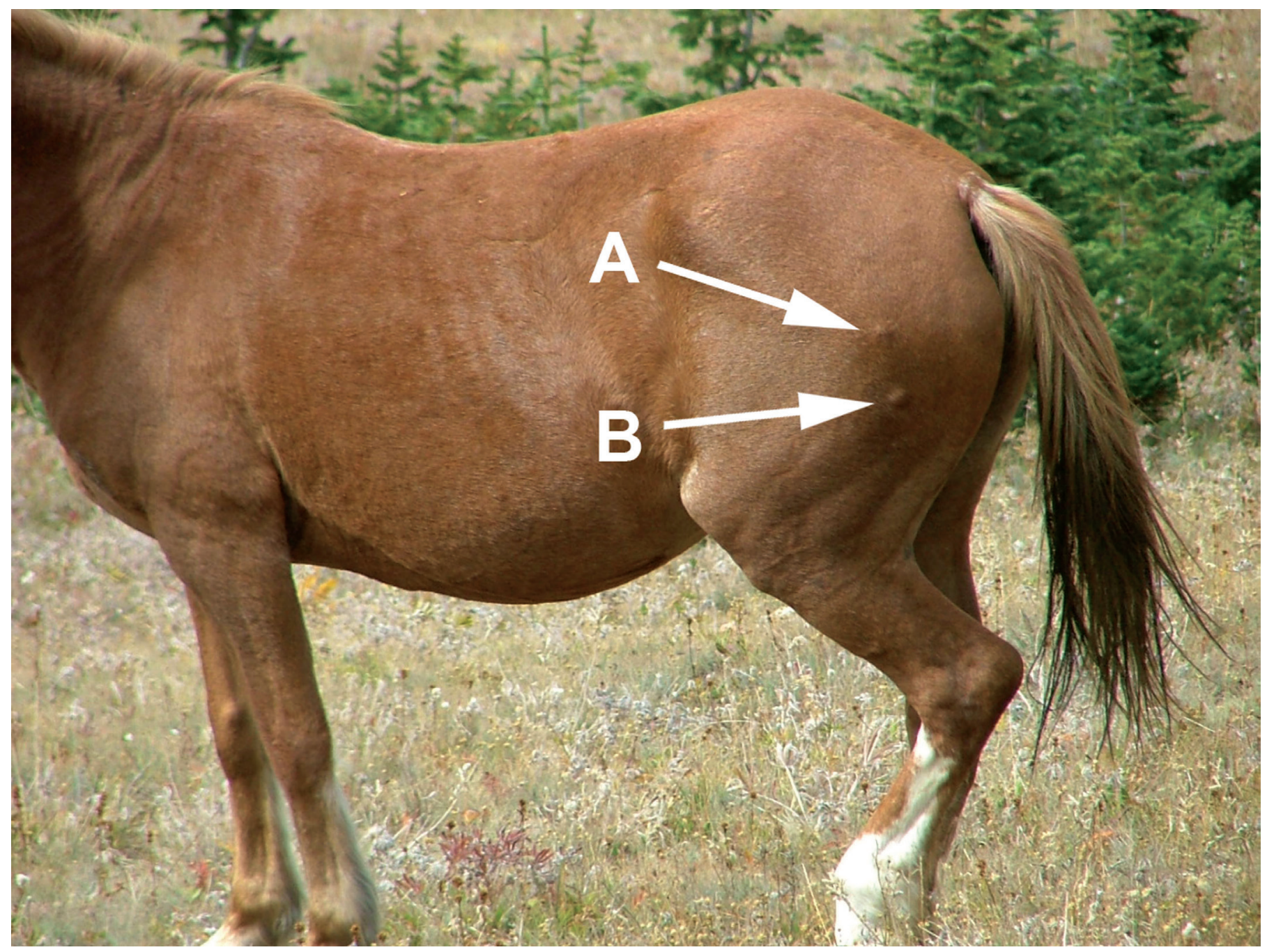

Figure 2. Two nodules observed on Pryor Mountain horse \#9105, 2 years $(A)$ and 56 days $(B)$ after booster injections delivered by $\mathrm{CO}_{2}$ blowgun.

and swelling and a nodule. In terms of injections, 35 (which includes the 10 mentioned above) of 306 (11.4 percent) resulted in multiple reactions, the most common combination being swelling and a nodule.

\section{Hand Injections}

The 72 injections by hand-held syringe, jabstick, or trocar at MCP resulted in two instances of swelling and no other reactions. In both cases, the swelling had disappeared by the time the animals were released back to the range. An additional 28 hand injections were given at LBC and PRY, resulting in only a single nodule, which formed on the day of the injection and persisted for about 150 days.

\section{Dart Injections}

\section{Dart Performance}

At LBC, 7 of 117 darts (6.0 percent) missed the animal completely and were not recovered. Four darts properly struck the target but were not recovered due to delayed ejection, rapid animal movement, thick vegetation, or some combination of these factors. Thus, 11 darts at LBC (9.4 percent of all darts fired) were not recovered. Similar data for PRY are incomplete and therefore are not reported here; however, due to the relatively short range of most shots at PRY, we believe that the unrecovered dart rate was likely lower than that at $\mathrm{LBC}$. 
The seven darts that missed the animal completely had no opportunity to discharge the drug properly and are thus not included in our assessment of dart performance (table 2). Based on the fact that the four other unrecovered darts struck the target properly, we assumed that they also functioned properly. Thus, for LBC and PRY combined, 278 injections were delivered remotely by dart from 2002 to 2007, and in 253 cases (91.0 percent) we judged that the injection was delivered properly (table 2). In 19 cases (6.8 percent), the dart either failed to discharge (the plunger was not depressed, two cases), partially discharged (the plunger was only partially depressed, three cases), split (the plastic portion split longitudinally, two cases; fig. 3), or came apart (the dart separated at the junction of the plastic and metal, 12 cases; fig. 3). In an additional six cases, the needle either broke off (three cases; fig. 3 ) or the dart hit bone (as evidenced by bone tissue in the recovered needle, three cases). When darts hit bone or came apart, the needles nevertheless fell free of the horse. In the few instances where the needle broke off, we do not know its fate. However, those three cases resulted in two nodules, both of which disappeared over time. The three injections where the dart hit bone cannot be considered a malfunction of the dart itself; excluding these three cases, 253 of 275 darts (92.0 percent) functioned properly.
Table 2. Performance of darts used in delivering the immunocontraceptive vaccine.

\begin{tabular}{lccc}
\hline & \multicolumn{2}{c}{ Number of darts } & \\
\cline { 2 - 3 } \multicolumn{1}{c}{ Dart performance } & LBC & PRY & \% of total \\
\hline Bone plug & 0 & 3 & 1.1 \\
Came apart & 5 & 7 & 4.3 \\
Did not discharge & 1 & 1 & 0.7 \\
Functioned & 102 & 151 & 91.0 \\
Needle broke off & 2 & 1 & 1.1 \\
Partially discharged & 0 & 3 & 1.1 \\
Split & 0 & 2 & 0.7 \\
\hline Total & 110 & 168 & 100.0 \\
\hline
\end{tabular}

\section{Frequency of Reactions}

Abscesses were relatively rare, resulting from at most 5-6 percent of the injections by dart (table 3). Most abscesses disappeared within 90 days of darting, though one persisted at PRY for more than 181 days. Nodules were both more frequent and more persistent than abscesses. Approximately 25 percent

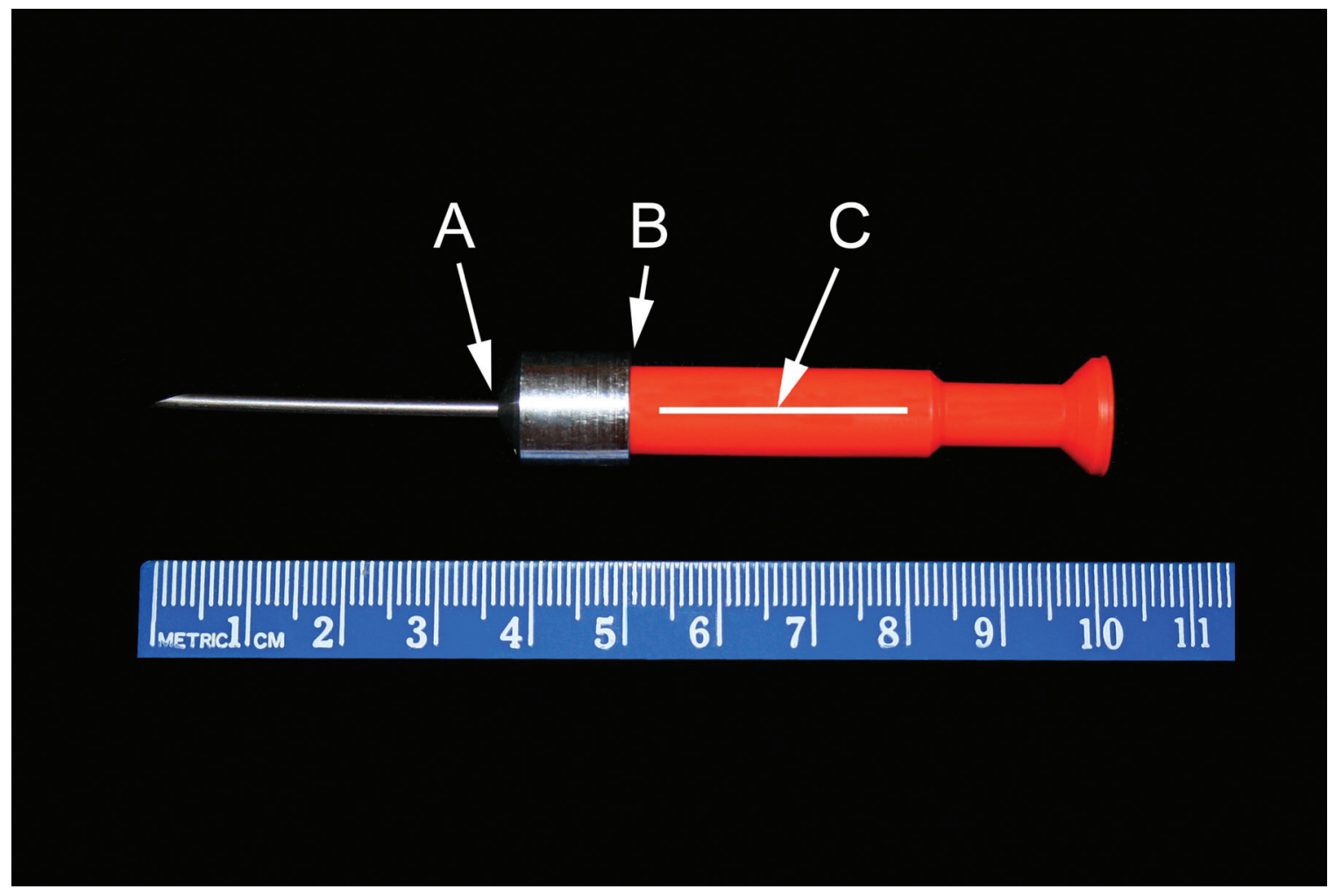

Figure 3. Example of a dart used for all injections. A is the point at which needles broke off, B is the point at which the metal separated from the plastic, and $C$ illustrates the position of a typical longitudinal split in the cylinder. 
of darts at both study areas resulted in nodules, and some nodules persisted into the fifth year. Most, however, eventually disappeared. Swelling resulted from about 11 percent of injections by dart at LBC and about 33 percent at PRY. At both study areas, swelling rarely persisted for more than 30 days and never for more than 90 days. Stiffness was recorded for 1.4 percent of the observations at LBC and 11.7 percent at PRY. In all cases, stiffness disappeared within the first 30 days.

\section{Relation of Reactions to Covariates}

For nodules, the criterion of at least one observation from day 7 through day 90 postinjection resulted in 185 of the 278 injections delivered by dart being selected for the analysis, including 50 (of the 61 known; see table 1) cases where a nodule occurred ( 27.0 percent) and 135 cases (73.0 percent) where none was observed (table 4). There perhaps was weak evidence that abnormal dart trauma (bone plug or broken needle) resulted in a higher occurrence rate for nodules, but the sample size for abnormal dart trauma was very small $(n=4)$. There was no evidence for a relation between nodule occurrence and either adjuvant formulation, delivery method, or age of mare.
The criterion of at least one observation from day 0 through day 7 posttreatment resulted in selection of 151 injections for analysis of swelling, including 43 (of the 49 possible) injections where swelling was known to have occurred (28.5 percent; see table 1), and an additional 108 (71.5 percent) injections for which swelling was not recorded (table 5). There was no evidence for a relation between swelling and either dart trauma, adjuvant, or age of mare, but strong evidence that swelling was more frequently observed when darts were delivered by blowgun than when they were delivered by rifle. Most (91.7 percent) of the 157 injections delivered by blowgun were at PRY.

Because the same criterion was used to select injections for analysis of both swelling and stiffness, the same 151 observations were chosen for both types of reactions. In the case of stiffness, this criterion resulted in the selection of 14 (of the 15 possible) injections known to have caused stiffness $(9.3$ percent; see table 1) and an additional 137 injections (90.7 percent) for which stiffness was not recorded (table 6). There was no apparent relation between stiffness and any of the covariates, though there were again few instances of abnormal dart trauma.

Table 3. Percentage of injection sites exhibiting abscesses, nodules, swelling, or stiffness as a function of time after injection. Only injections delivered by dart are included. Multiple observations of an injection site in a period were counted as a single observation in determining sample size $(n)$. The reaction was coded as present if it was recorded for any observation during the time period.

$[-=$ not applicable $]$

\begin{tabular}{|c|c|c|c|c|c|c|}
\hline HMA & $\begin{array}{l}\text { Time after } \\
\text { injection }\end{array}$ & $n$ & $\%$ Abscess & $\%$ Nodule & $\%$ Swelling & $\%$ Stiffness \\
\hline \multirow[t]{7}{*}{ LBC } & 0-30 days & 73 & 5.5 & 12.3 & 11.0 & 1.4 \\
\hline & 91-180 days & 16 & 0.0 & 18.8 & 0.0 & 0.0 \\
\hline & 181-365 days & 62 & 0.0 & 12.9 & 0.0 & 0.0 \\
\hline & Year 3 & 62 & 0.0 & 6.5 & 0.0 & 0.0 \\
\hline & Year 4 & 49 & 0.0 & 6.1 & 0.0 & 0.0 \\
\hline & Year 5 & 27 & 0.0 & 0.0 & 0.0 & 0.0 \\
\hline & Year 6 & - & - & - & - & - \\
\hline \multirow{6}{*}{ PRY } & 181-365 days & 66 & 1.5 & 22.7 & 0.0 & 0.0 \\
\hline & Year 2 & 76 & 0.0 & 19.7 & 0.0 & 0.0 \\
\hline & Year 3 & 21 & 0.0 & 28.6 & 0.0 & 0.0 \\
\hline & Year 4 & 21 & 0.0 & 19.0 & 0.0 & 0.0 \\
\hline & Year 5 & 38 & 0.0 & 5.3 & 0.0 & 0.0 \\
\hline & Year 6 & 11 & 0.0 & 0.0 & 0.0 & 0.0 \\
\hline
\end{tabular}


Table 4. Relation between occurrence of nodules and the covariates dart trauma, adjuvant, delivery method, and age of mare ( $n=185$ injections).

\begin{tabular}{|c|c|c|}
\hline \multicolumn{3}{|c|}{ Frequency distribution ${ }^{1}$} \\
\hline \multirow[b]{2}{*}{ Covariate } & \multicolumn{2}{|c|}{ Nodule occurrence } \\
\hline & No & Yes \\
\hline \multicolumn{3}{|l|}{ Dart trauma } \\
\hline Abnormal & $1(25.0)^{2}$ & $3(75.0)$ \\
\hline Normal & $134(74.0)$ & $47(26.0)$ \\
\hline \multicolumn{3}{|l|}{ Adjuvant } \\
\hline FCA & 24 (70.6) & $10(29.4)$ \\
\hline FIA & $100(74.1)$ & $35(25.9)$ \\
\hline FMA & $11(68.7)$ & $5(31.3)$ \\
\hline \multicolumn{3}{|c|}{ Delivery method } \\
\hline Blowgun & $86(70.5)$ & $36(29.5)$ \\
\hline Rifle & $49(77.8)$ & $14(22.2)$ \\
\hline
\end{tabular}

\begin{tabular}{lcccc}
\hline & \multicolumn{3}{c}{ Logistic analysis } \\
\hline \multicolumn{1}{c}{ Covariate } & $P$ & \multicolumn{3}{c}{ Odds ratio } \\
\cline { 3 - 5 } & & Point Estimate & $95 \%$ Wald Confidence Limits \\
\hline Dart trauma & 0.07 & 8.729 & 0.874 & 87.235 \\
$\quad$ Abnormal vs. normal & & & & \\
Adjuvant & 0.64 & 0.820 & 0.313 & 2.148 \\
$\quad$ FIA vs. FCA & 0.87 & 0.998 & 0.254 & 3.922 \\
FMA vs. FCA & & & & 2.957 \\
Delivery method & 0.54 & 1.297 & 0.568 & 1.092 \\
$\quad$ Blowgun vs. rifle & 0.68 & 1.015 & 0.944 & \\
Age of mare & &
\end{tabular}

${ }^{1}$ Age of mare was analyzed as a continuous variable and thus is not included in this portion of the table.

${ }^{2}$ Numbers in parentheses $=$ percentage of row total. 
Table 5. Relation between occurrence of swelling and the covariates dart trauma, adjuvant, delivery method, and age of mare ( $n=151$ injections).

\begin{tabular}{|c|c|c|}
\hline \multicolumn{3}{|c|}{ Frequency distribution ${ }^{1}$} \\
\hline \multirow[b]{2}{*}{ Covariate } & \multicolumn{2}{|c|}{ Swelling occurrence } \\
\hline & No & Yes \\
\hline \multicolumn{3}{|l|}{ Dart trauma } \\
\hline Abnormal & $3(60.0)^{2}$ & $2(40.0)$ \\
\hline Normal & $105(71.9)$ & $41(28.1)$ \\
\hline \multicolumn{3}{|l|}{ Adjuvant } \\
\hline FCA & $16(66.7)$ & $8(33.3)$ \\
\hline FIA & $89(74.2)$ & $31(25.8)$ \\
\hline FMA & $3(42.9)$ & $4(57.1)$ \\
\hline \multicolumn{3}{|c|}{ Delivery method } \\
\hline Blowgun & $55(61.1)$ & $35(38.9)$ \\
\hline Rifle & $53(86.9)$ & $8(13.1)$ \\
\hline
\end{tabular}

\begin{tabular}{|c|c|c|c|c|}
\hline \multicolumn{5}{|c|}{ Logistic analysis } \\
\hline Covariate & $P$ & Point Estimate & $95 \% \mathrm{Wa}$ & ce Limits \\
\hline \multicolumn{5}{|l|}{ Dart trauma } \\
\hline Abnormal vs. normal & 0.55 & 1.856 & 0.243 & 14.167 \\
\hline FMA vs. FCA & 0.21 & 3.232 & 0.529 & 19.741 \\
\hline \multicolumn{5}{|l|}{ Delivery method } \\
\hline Blowgun vs. rifle & 0.001 & 5.023 & 1.921 & 13.136 \\
\hline Age of mare & 0.17 & 0.949 & 0.882 & 1.022 \\
\hline
\end{tabular}

${ }^{1}$ Age of mare was analyzed as a continuous variable and thus is not included in this portion of the table.

${ }^{2}$ Numbers in parentheses $=$ percentage of row total. 
Table 6. Relation between occurrence of stiffness and the covariates dart trauma, adjuvant, delivery method, and age of mare ( $n=151$ injections).

\begin{tabular}{lcr}
\hline & \multicolumn{2}{c}{ Frequency distribution $^{1}$} \\
\cline { 2 - 3 } Covariate & \multicolumn{2}{c}{ Stiffness occurrence } \\
\hline Dart trauma & Yes \\
Abnormal & $4(80.0)^{2}$ & \\
Normal & $133(91.1)$ & $1(20.0)$ \\
Adjuvant & & $13(8.9)$ \\
FCA & $19(79.2)$ & \\
FIA & $112(93.3)$ & $1(20.8)$ \\
FMA & $6(85.7)$ & \\
Delivery method & & $11(13.3)$ \\
Blowgun & $78(86.7)$ & $2(3.3)$ \\
Rifle & $59(96.7)$ & \\
\hline
\end{tabular}

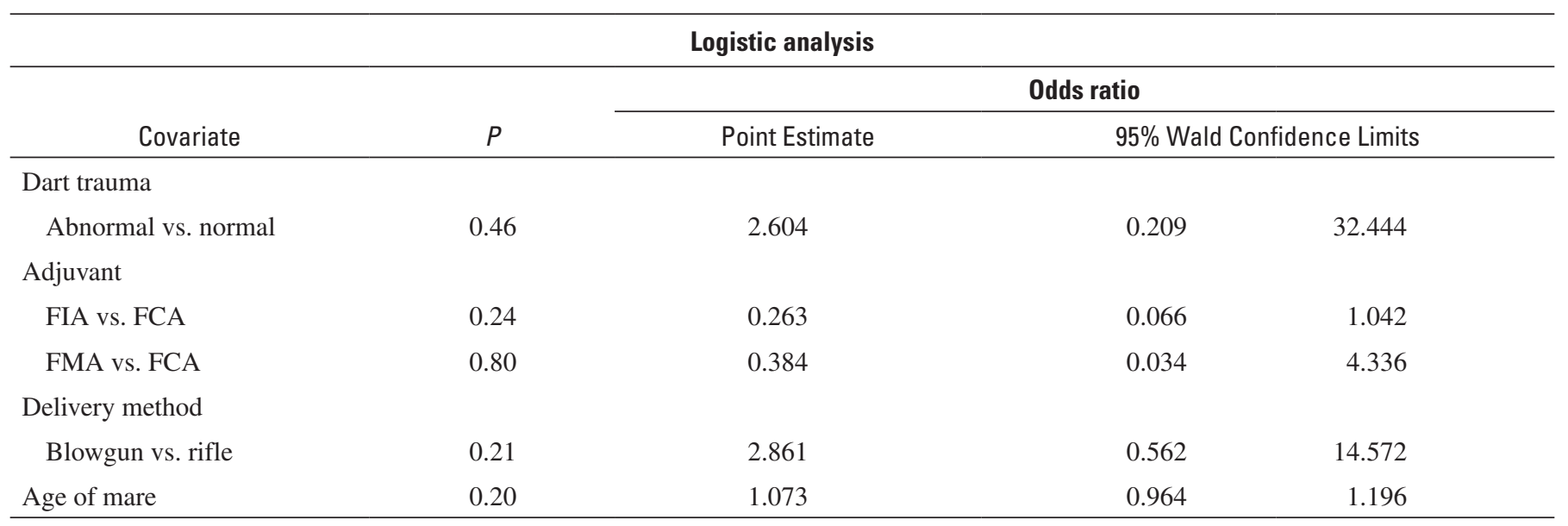

\footnotetext{
${ }^{1}$ Age of mare was analyzed as a continuous variable and thus is not included in this portion of the table.
}

${ }^{2}$ Numbers in parentheses $=$ percentage of row total. 


\section{Discussion}

\section{Darting}

Excluding the three injections that resulted in bone plugs, the overall failure rate of darts was 8 percent, but failures were not distributed evenly through time. In 2002-2003, 20 of 112 darts (17.9 percent) failed to function properly. Following changes in manufacturing, the failure rate in 2004-2007 dropped to 2 of 163 (1.2 percent). This was an important improvement in the dart manufacturing process given the time and effort expended to find and dart individual horses. The small number of darts lost on the range presumably represent little biological hazard should they be found because impact with the ground or other natural objects probably triggered the release mechanism in the dart and discharged the contents. The very small amounts of PZP and adjuvant discharged also presumably do not pose an environmental contamination threat. The physical hazards of darts, as well as pieces of darts that were unrecoverable (broken needles or needle/cap separations), could pose minor danger if found by visitors simply due to the sharp nature and aging metal present. However, given the intensity of search effort by the darters at the time of operations, it is unlikely that an unrecovered dart would be discovered, even if another person passed by the exact location in these remote areas.

\section{Abscesses}

Our results for injections delivered by hand-held syringe or jabstick are consistent with the scant information on abscesses reported in the literature for equids. We observed no abscesses in 72 hand injections of 36 mares at MCP, and no abscesses (but a single nodule) in 28 hand injections at LBC and PRY combined. Turner and others (1997) hand-injected 60 mares in the gluteus muscle with PZP and FCA, and held them in corrals for 30 days awaiting a booster injection. No abscesses were observed in this 30-day period, and the authors further concluded that abscesses were unlikely to have occurred in an additional group of mares that were treated with a single injection of PZP and FCA and released within 72 hours posttreatment. In a similar experiment, Turner and others (2001) hand-injected 95 mares in the gluteus muscle with PZP and FCA and an additional 60 mares in the same location with PZP, FCA, and a carbomer adjuvant. These 155 mares were held in corrals for 13-17 days awaiting a booster treatment, and no abscesses were observed during this period. Further observations of some of these mares after release showed no injectionsite marks, leading the authors to conclude that abscesses had not occurred. Lyda and others (2005) treated 7 mares with PZP plus FCA and 8 mares with PZP plus FMA; all 15 mares received a booster injection of PZP plus FIA 27 days later. All injections were delivered by hand in the hip or gluteal muscles. The 30 total injections in their study resulted in one abscess (3.3 percent of injections) following a booster with FIA in a mare initially treated with FMA.
Thus, it appears that abscesses are rare in horses for injections of PZP and any of the formulations of Freund's adjuvant where the injections are delivered by hand in the hip region. The location of the injection may be important, however. Lyda and others (2005) cited a personal communication from I.K. Liu indicating that abscesses can occur more frequently in horses receiving injections of PZP and FCA in the neck.

Information on abscesses resulting from injections delivered remotely to horses is similarly scarce. Kirkpatrick and others (1990) darted mares at Assateague Island National Seashore with PZP and FCA ( $n=26$ mares), followed by PZP and FIA boosters ( $n=26$, injection $2 ; n=18$, injection 3 ). Following the third injection (with FIA), they observed three abscesses, or a frequency of 4.3 percent (in 70 injections). Following several additional years of treatment at Assateague, the number of abscesses was reported as either two (Turner and Kirkpatrick, 2002) or three (Lyda and others, 2005) in a total of 381 injections ( 0.5 or 0.8 percent). Interestingly, both of these later publications attributed only one of the abscesses to an injection containing FIA. In any case, the frequency of occurrence of abscesses was low.

Our results for frequency of occurrence of abscesses in mares darted at PRY ( 0.8 percent; table 3$)$ were very similar to those reported above, but somewhat higher (5.5 percent) at $\mathrm{LBC}$. The higher rate at $\mathrm{LBC}$ is mostly a result of four abscesses occurring in a single mare that was clearly prone to reaction. In addition, however, our approach to calculating frequency of occurrence of reactions, necessitated by the fact that we were unable to observe injection sites on a regular schedule, is strictly valid only if the observations can be considered a random sample of all of the injection sites present in an interval. This is probably not the case, because field personnel were instructed to monitor injection sites where there was a known reaction as closely as possible until the reaction was resolved, and then record observations only opportunistically. In fact, the mean number of observations for injection sites that showed a reaction (5.10) was slightly higher than the mean number of observations for injection sites that did not show a reaction (4.53; generalized linear model with Poisson distribution, $P=$ 0.03 ). Thus, it is likely that our results for frequency of occurrence of all reaction types are biased somewhat high.

Kirkpatrick and others (1990) also reported that the three abscesses they observed formed within about 48 hours of the injection and healed completely within 14 days. The single abscess observed in the study by Lyda and others (2005) appeared 1 month after a booster inoculation; time until healing was not reported. While our observations on the timing of appearance and disappearance of abscesses are not as precise, we do know that one abscess became visible at least 24 days posttreatment and that six of the eight abscesses observed were present on day 15. Additionally, one abscess was present at day 77 postinjection, and another at day 329. Thus, it appears that abscesses can form as much as a month posttreatment and can occasionally persist for much longer than has been reported previously. 


\section{Other Reactions}

We are unaware of any published information on occurrence of other injection-site reactions in equids treated with PZP. This is curious, particularly for nodules, which in our study were fairly common and sometimes persisted for long periods. It is unclear whether reactions similar to what we termed nodules simply did not occur in other studies, or perhaps were considered too inconsequential to report. Similar reactions have occurred in other species, however. Turner and others (1992, p. 155), working on white-tailed deer (Odocoileus virginianus), reported that "a raised area of about $20 \mathrm{~mm}$ in diameter developed in the final injection site on 3 does." These reactions disappeared in 8-10 days in two cases and after 5 weeks in the third. Patton and others (2005, p. 160) also mention that the Freund's adjuvants often cause formation of a small (marble size) granuloma at the injection site, but they do not provide any examples.

\section{Covariates}

We were unable to detect a relation between any of the reactions we observed and the adjuvant used. Coupled with the fact that reactions are rare for injections delivered by hand, this suggests that most reactions are probably the result of trauma associated with dart delivery, or a combination of dart trauma and adjuvant. With that observation in mind, we were somewhat surprised to find a higher probability of swelling when darts were delivered by blowgun, which was used at closer ranges and allowed for variable power. The average distance from which darts were fired by blowgun was $11.8 \pm$ $0.24 \mathrm{~m}$, whereas for darts fired by rifle it was $31.8 \pm 1.03 \mathrm{~m}$, and the majority of the shots fired by blowgun (144 of 157, or 91.7 percent) were at PRY, where horses are generally more approachable than at LBC. Greater approachability at PRY probably led to both more frequent use of the blowgun and greater ability to detect swelling.

\section{Conclusion}

PZP is a promising management tool for limiting population growth in wild horses; however, as with any management tool, side effects, practicality of use, and physiological and biological implications must also be considered. PZP has been clinically tested for safety and some potential physiological side effects in both domestic and wild equids (Liu, 1989; Kirkpatrick and others, 1992, 1995, 1996; Kirkpatrick and Turner, 2002;), but there is less information available regarding safety in field applications. Currently, the most time-efficient method for applying PZP is by hand-delivered injection of 2-year pellets when horses are gathered. We observed only two instances of swelling from this formulation. Use of remotely delivered, 1-year PZP is generally limited to populations where individual animals can be accurately identified and repeatedly approached. This formulation produced injection-site reactions of varying intensity, though none of the observed reactions appeared debilitating to the animals. The longer term nodules observed did not appear to change any animal's range of movement or locomotor patterns and in most cases did not appear to differ in magnitude from naturally occurring injuries or scars. We were unable to perform histological examinations of these nodules, but they may be similar to granulomas reported by other investigators following administration of Freund's adjuvant. Further analyses should be considered to determine whether they pose any long-term physiological threat to the animal. Injection-site reactions represent only one of the potential effects of PZP on horses. Other factors, such as treatment efficacy, long-term ovarian function, individual and social behavior, and seasonality of parturition by post-treated mares are also important considerations for the assessment of PZP as a management tool.

\section{Acknowledgments}

This research was funded by the USGS Wildlife Program and conducted through a cooperative effort between the USGS Fort Collins Science Center, the BLM Wild Horse and Burro Program, the USDA's Animal and Plant Health Inspection Service (APHIS), the National Park Service (NPS), and Colorado State University. We give special thanks to the field technicians, contractors, and volunteers who spent countless hours searching for horses, often under difficult conditions: Hanem Abouelezz, Laura Caldwell, Melissa Esser, Marty Felix, Kayla Grams, Patty Grigsby, Susan Hahn, Billie Hutchings, Georgia Manus, Jane Nibler, Christina Petrandis, Phyllis Preator, Jennifer Severude, and Gerald Thygerson. We thank Jay Kirkpatrick, Kim Frank, and Robin Lyda of the Science and Conservation Center, ZooMontana, for supplying liquid PZP and for training our staff to safely handle and deliver it remotely in the field, and John Turner, Jr., at the University of Toledo College of Medicine for formulating and administering the PZP pellets. Logistical support was graciously provided by the BLM's Grand Junction, Cody, and Billings Field Offices as well as NPS's Bighorn Canyon National Recreation Area. In particular, we thank Linda Coates-Markle, Jim Dollerschell, and Tricia Hatle from the BLM, and Rick Lasko and Cassity Bromley from NPS for coordination, office space, equipment, and endless technical support. Thanks to Albert Kane at APHIS for his veterinary and statistical advice and to Dean Bolstad and Alan Shepherd for coordinating the BLM wild horse research efforts and providing management perspectives. Gregor Auble, Dean Bolstad, Brian Cade, Albert Kane, Alan Shepherd, John Turner, and Bea Wade provided many useful comments on earlier drafts of this report. 


\section{References Cited}

Asa, C.S., 2005, Types of contraception-The choices, in Asa, C.S., and Porton, I.J., eds., Wildlife contraception-Issues, methods, and applications: Baltimore, Md., The Johns Hopkins University Press, p. 29-52.

Broderson, J.R., 1989, A retrospective review of lesions associated with the use of Freund's adjuvant: Laboratory Animal Science, v. 39, p. 400-405.

Chapel, H.M., and August, P.J., 1976, Report of nine cases of accidental injury to man with Freund's complete adjuvant: Clinical and Experimental Immunology, v. 24, p. $538-541$.

Claassen, E., de Leeuw, W., de Greeve, P., Hendriksen, C., and Boersma, W., 1992, Freund's complete adjuvant-An effective but disagreeable formula: Research in Immunology, v. 43, p. 478-483.

Eberhardt, L.L., Majorowicz, A.K., and Wilcox, J.A., 1982, Apparent rates of increase for two feral horse herds: Journal of Wildlife Management, v. 46, p. 367-374.

Garrott, R.A., Siniff, D.B., and Eberhardt, L.L., 1991, Growth rates of feral horse populations: Journal of Wildlife Management, v. 55, p. 641-648.

Garrott, R.A., and Taylor, L., 1990, Dynamics of a feral horse population in Montana: Journal of Wildlife Management, v. 54, p. 603-612.

Kirkpatrick, J.F., and Frank, K.M., 2005, Contraception in freeranging wildlife, in Asa, C.S., and Porton, I.J., eds., Wildlife contraception - issues, methods, and applications: Baltimore, Md., The Johns Hopkins University Press, p. 195-221.

Kirkpatrick, J.F., Liu, I.K.M., and Turner, J.W., Jr., 1990, Remotely-delivered immunocontraception in feral horses: Wildlife Society Bulletin, v. 18, p. 326-330.

Kirkpatrick, J.F., Liu, I.M.K., Turner, J.W., Jr., Naugle, R., and Keiper, R., 1992, Long-term effects of porcine zonae pellucidae immunocontraception on ovarian function in feral horses (Equus caballus): Journal of Reproduction and Fertility, v. 94, p. 437-444.

Kirkpatrick, J.F., Naugle, R., Liu, I.K.M., Bernoco, M., and Turner, J.W., Jr., 1995, Effects of seven consecutive years of porcine zona pellucida contraception on ovarian function in feral mares: Biology of Reproduction Monograph Series 1, Equine Reproduction VI, p. 411-418.

Kirkpatrick, J.F., and Turner, A., 2002, Reversibility of action and safety during pregnancy of immunization against porcine zona pellucida in wild mares (Equus caballus): Reproduction Supplement, v. 60, p. 197-202.
Kirkpatrick, J.F., Turner, J.W., Jr., Liu, I.K.M., and FayrerHosken, R., 1996, Applications of pig zona pellucida immunocontraception to wildlife fertility control: Journal of Reproduction and Fertility, Supplement 50, p. 183-189.

Leenaars, M., Koedam, M.A., Hendriksen, C.F.M., and Claassen, E., 1998, Immune responses and side effects of five different oil-based adjuvants in mice: Veterinary Immunology and Immunopathology, v. 61, p. 291-304.

Leenaars, P.P.A.M., Hendriksen, C.F.M., Angulo, A.F., Koedam, M.A., and Claassen, E., 1994, Evaluation of several adjuvants as alternatives to the use of Freund's adjuvant in rabbits: Veterinary Immunology and Immunopathology, v. 40, p. $225-241$.

Liu, I.K.M., Bernoco, M., and Feldman, M., 1989, Contraception in mares heteroimmunized with pig zonae pellucidae: Journal of Reproduction and Fertility, v. 85, p. 19-29.

Lyda, R.O., Hall, J.R., and Kirkpatrick, J.F., 2005, A comparison of Freund's complete and Freund's modified adjuvants used with a contraceptive vaccine in wild horses (Equus caballus): Journal of Zoo and Wildlife Medicine, v. 36, p. 610-616.

Mahi-Brown, C.A., Yanagimachi, R., Hoffman, J.C., and Huang, T.T.F., Jr., 1985, Fertility control in the bitch by active immunization with porcine zonae pelucidae - use of different adjuvants and patterns of estradiol and progesterone levels in estrous cycles: Biology of Reproduction, v. 32, p. 761-772.

Naugle, R.E., Rutberg, A.T., Underwood, H.B., Turner, J.W., Jr., and Liu, I.K.M., 2002, Field testing of immunocontraception on white-tailed deer (Odocoileus virginianus) on Fire Island National Seashore, New York, USA: Reproduction Supplement, v. 60, p. 143-153.

Patton, M.L., Jöchle, W., and Penfold, L.M., 2005, Contraception in ungulates, in Asa, C.S., and Porton, I.J., eds., Wildlife contraception-Issues, methods, and applications: Baltimore, Md., The Johns Hopkins University Press, p. 149-167.

Turner, A., and Kirkpatrick, J.F., 2002, Effects of immunocontraception on population, longevity and body condition in wild mares (Equus caballus): Reproduction Supplement, v. 60 , p. $187-195$.

Turner, J.W., Jr., Liu, I.K.M., Flanagan, D.R., Rutberg, A.T., and Kirkpatrick, J.F., 2001, Immunocontraception in feral horses-One inoculation provides one year of infertility: Journal of Wildlife Management, v. 65, p. 235-241.

Turner, J.W., Jr., Liu, I.K.M., and Kirkpatrick, J.F., 1992, Remotely delivered immunocontraception in captive white-tailed deer: Journal of Wildlife Management, v. 56, p. 154-157. 
Turner, J.W., Jr., Liu, I.K.M., and Kirkpatrick, J.F., 1996, Remotely delivered immunocontraception in free-roaming feral burros (Equus asinus): Journal of Reproduction and Fertility, v. 107, p. 31-35.

Turner, J.W., Jr., Liu, I.K.M., Rutberg, A.T., and Kirkpatrick, J.F., 1997, Immunocontraception limits foal production in free-roaming feral horses in Nevada: Journal of Wildlife Management, v. 61, p. 873-880.

U.S. Department of the Interior, Bureau of Land Management, 2001, Environmental Assessment and Gather Plan, Pryor Mountain Wild Horse Range, FY2001 Wild Horse Population Gather \& Selective Removal, EA MT-010-1-44: Billings, Mont., BLM Field Office.

U.S. Department of the Interior, Bureau of Land Management, 2002, Environmental Assessment Record and Gather Plan, Little Book Cliffs Wild Horse Range, CO-GJFO-02-32EA: Grand Junction, Colo., BLM Field Office.

U.S. Department of the Interior, Bureau of Land Management, 2004, McCullough Peaks HMA Gather Plan and Fertility Control Implementation, Environmental Assessment WY-020-E04-039: Cody, Wyo., BLM Field Office.

Publishing support provided by:

Denver Publishing Service Center

For more information concerning this publication, contact:

Center Director, USGS Fort Collins Science Center

2150 Centre Ave., Bldg. C

Fort Collins, CO 80526-8118

(970)226-9398

Or visit the Fort Collins Science Center Web site at: http://www.fort.usgs.gov/ 
趈

잉

ฏ

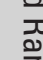

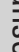

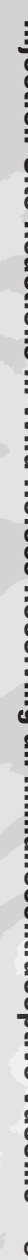

